\title{
On the Construction of Teachers' Professional Quality-oriented English Practice Teaching System-Exemplified with the English Major of Sichuan University of Arts and Science*
}

\author{
Kang Liu \\ Sichuan University of Arts and Science, Dazhou 635000, Sichuan, China
}

\begin{abstract}
Professional quality is the core element of training talents. Developing elegant professional qualities is the thirsty demand for students and the great mission of higher education. With the main purpose to train would-be qualified English teachers, English major is supposed to build an English practice teaching system directed by teachers' professional quality on the basis of Certification Standard of Secondary Education, so that students can gradually follow professional principles, understand teaching methodology, start educational task and seek self-improvement in practice teaching and learning activities, subsequently helping to lay a solid foundation for students' future professional ability development.
\end{abstract}

Index Terms—English teachers, professional qualities, practice teaching, content system

\section{INTRODUCTION}

Practice teaching is an important measure to adhere to the concept of scientific development and fully rejuvenating the country with aid of advanced science, education and talents. Enforcing practice teaching is an educational plan for colleges and universities to further deepen teaching reform, improve ability and level of personnel training, meet the needs of economic and social development for high-quality innovative talents, which is a powerful starting point for ensuring the improvement of undergraduate teaching quality. The document of National Medium and Long-Term Education Reform and Development Program (2010-2020) clearly proposes that colleges and universities should vigorously strengthen practice teaching, including professional probation and graduation practice and the construction of practice teaching bases. The Ministry of Education also sponsors to attach great importance to the practice links and improve students' practical ability in the issue of Several Opinions on Further Deepening Undergraduate Teaching Reform and Improving Teaching Quality in an All-round Way. In recent years, colleges and universities have continuously stepped up the pace of practice teaching reform, improved practice teaching conditions, and strengthened practice teaching administration. Practice teaching has received unprecedented attention and achieved good results.

\section{THEORETICAL Basis of ENGLISH PRACTICE TEACHING}

Language learning cannot be achieved without a proper learning environment, and language learning environment is an important criterion to distinguish "the second language" from "the foreign language". The second language learners study and live in the target language environment, and the natural and real environment enables learners to acquire the target language gradually and unconsciously. However, Chinese students learn English in their own country mainly through purposeful and conscious classroom teaching activities to learn systematic language knowledge and grammar rules with obvious instrumental and utilitarian learning motivation (Shi, 2009). From the perspective of language input, Chinese students lack a natural language input environment when learning English in their own country, and the amount of language input is quite limited, so English teaching in China is termed as foreign language teaching, and there needs to set up a special language practice teaching environment to train learners' language skills and improve learners' English proficiency.

\section{A. Theories of Acquisition and Learning}

According to Krashen, an American linguist, language acquisition does not require extensive use of conscious grammatical rules or tedious drill. For study of target language, acquisition requires meaningful interaction in the natural communication in which speakers are not concerned with the form of their utterances but with the messages they are communicating and understanding (Krashen, 1982). This theory holds that there are two ways of language study: "acquisition" and "learning". Acquisition is a subconscious process, which allows learners to participate in social

\footnotetext{
${ }^{*}$ This article is funded by Sichuan Foreign Language Literature Research Center (Programme No: SCWYH20-22).
} 
activities and unconsciously absorb and use language in the exchange of information. Learning is to do systematic training work in listening, speaking, reading and writing through teaching materials under the arranged teaching procedures in order to deepen the understanding of language forms and grammar rules. It can be seen that both "acquisition" and "learning" need objective environment for language information input and output. Therefore, language learners should not only pay attention to learning a lot of language knowledge from teaching classroom in "weak context", but also get more language input from language practice activities in "strong context" as much as possible and constantly improve skills of language use, so as to finally achieve the goal of internalizing the learned language (Duan, 2009).

\section{B. Theory of Constructivist Learning}

Constructivism holds that knowledge is not acquired through teachers' teaching, but through the meaning construction realized by interpersonal cooperation activities with the help of others in a social and cultural background. Constructivist learning theory first emphasizes the central position of students and holds that students are the main body of cognition. Whether students can acquire more knowledge is determined by the ability of learners to explore and construct the meaning of relevant knowledge. What plays a decisive role is not the abilities of learners to obtain book knowledge or abilities of teachers to teach. This theory stresses that learning situation and cooperative learning play an important role in the construction of knowledge and meaning. In the teaching process, teachers design students' desirable learning resources, learning strategies, cognitive tools and cultural situations of language learning from the perspectives of "situation", "cooperation", "conversation" and "resources". English is a highly practical subject, and its accumulation of language knowledge, improvement of language skills and cultivation of language awareness need to be constructed and formed in a large sum of language practice. Only in the real pragmatic background, with help of social interaction and necessary learning resources, can students actively and effectively construct knowledge and reorganize the original knowledge structure to achieve their learning goals.

\section{BASIC REQUIREMENTS OF ENGLISH TEACHERS’ PROFESSIONAL QUALITIES}

Education shoulders three major functions: it firstly aims to impart the existing knowledge of human beings, the second is to train learners' social abilities, and the third is to cultivate learners' personal qualities (Shu \& Zhuang, 1999). Han Yu (an ancient Chinese writer in Tang Dynasty) said that the teacher is one who preaches truth, teaches knowledge and dispels doubts. Normal English major is mainly committed to cultivating English teachers and English teaching administrative talents in primary and secondary schools with sound personalities, firm beliefs, solid English language foundation, extensive cultural knowledge and profound humanistic qualities. After several years of study, Students are hoped to have a good command of bilingual cultures, strong expressing abilities, proficient English teaching ability, innovative thinking abilities, autonomous learning abilities, and develop a high sense of social responsibility and continuous enterprising spirit. As a foreign language teacher, there are following aspects of qualities for attention:

\section{A. Firm Ideological Qualities}

Foreign language teachers should stick to a firm and correct political direction, understand and actively practice social core values, forming a high degree of ideological, political, theoretical and emotional identities with Chinese characteristics. They are supposed to love education and cherish noble teachers' moralities, social responsibilities, good educational ideals and great instructing emotions. English teachers are to learn about the national strategies and policies of education development, abide by the national education laws and regulations, nurture the willingness and positive emotion, develop correct attitude and correct values to contribute to education. Besides, an English teacher is able to respect students' personalities and become a guide for students to acquire knowledge, uplift abilities, sharpen wisdom and improve characters.

\section{B. Solid Professional Qualities}

First of all, foreign language teachers should have well-knit frame of basic knowledge, language skills and comprehensive abilities to use English. Secondly, they should have a broad view of educational knowledge, including scientific knowledge, social knowledge, administrative knowledge, etc. To the greatest extent, rich educational knowledge can stimulate teaching passion and motivation. In addition, foreign language teachers are required to have certain theoretical literacy, mastering educational theories, modern linguistic theories, foreign language learning and teaching theories etc. Such theories contribute to their English teaching and academic researches.

\section{Profound Humanistic Qualities}

Foreign language teachers must know Chinese history, humanities and social sciences, natural sciences and art education. They equally keep learning Chinese traditional culture and culture of English-speaking countries, trying to have a broad international vision and strong cross-cultural communication abilities. Thus, they can actively direct students to enhance their sense of identity and self-confidence in Chinese culture in the multicultural background by the way of telling Chinese stories and spreading Chinese culture in English.

In addition, foreign language teachers should have a scientific attitude of seeking truth from facts, a good sense of teamwork, physical and mental health and optimistic spirits. The professional qualities of foreign language teachers 
determine that the English practice teaching system is required to closely focus on professional training objectives and talent specifications on the basis of professional characteristics, social needs and students' employment demands.

\section{PRofessional Quality-ORIENTEd ENGlish PRACTICE TEACHING SySTEM}

In the document of Some Opinions on the Reform of Undergraduate Education for Foreign Language Majors in the 21st Century, the Steering Committee of Foreign Language Major in Colleges and Universities emphasizes that the theoretical knowledge of classroom learning be applied to extra-curricular practical activities so as to cultivate students' cross-cultural abilities, critical thinking abilities, innovative abilities and abilities to analyze and solve problems by using the knowledge they have learned (1998). The Syllabus for English Major in Colleges and Universities also requires that English classroom teaching should be linked with extracurricular practical activities because extracurricular practice, as the expansion of classroom teaching and learning, plays an important part for cultivating and developing students' abilities and comprehensive qualities in all aspects (2000).

\section{A. Principles of Practice Teaching}

1. Principle of Integration

English practice teaching system not only optimizes the curriculum structure from the requirements of society for the all-round development of talents' knowledge, quality and ability, but also ensures the coordinated development of teaching content, teaching means, teaching practice, teaching management and teaching supplies. Attention should be paid to creating a close link between practical and theoretical teaching, so that come into being a good atmosphere and environment in which classrooms, laboratories and practice teaching bases are integrated to combine teaching, learning, practicing into one unity.

2. Career-oriented Principle

To satisfy the demands of professional qualities, English teachers need to have strong English listening, speaking, reading, writing and translating skills. Moreover, they try to be proficient with Chinese and Western cultures, acquire good cross-cultural communication skills, master modern information technology and make the best of professional knowledge to conduct speculative, innovative and scientific research. Therefore, it is reasonable that the teaching contents and training objectives of English practice teaching system contribute to the professional needs of English teachers, which runs through the whole teaching process to help cultivate English professionals with adept language application and strong employing competitiveness.

3. Principle of Modularization

Modular teaching mode was developed by the International Labor Organization in the early 1970s, which focuses on on-site teaching and training skills. According to the requirements of English practice teaching objectives, plans and tasks, the student-centered practice teaching contents can fall into training modules of specialty skills, teaching skills, educational probation, moral practice, and academic training, etc.

\section{B. Components of Practice Teaching Content}

Practice teaching for English major centers on cultivating English teachers' professional abilities, which is divided into five parts: moral education practice, practice of specialty skill, practice of normal skill, teaching practice and academic research practice.

1. Moral Education Practice

A moral practice program is consisted of different social practical activities such as military training, social investigation and labor experience, which aims to deepen students' understanding of life, improve students' abilities to adapt to social situations and temper characters. Practice of moral education devotes to establish a firm political direction, scientific view of the world and moral values, guiding college students to edify their thoughts, enriching their spiritual life, improving their moral realm and increasing their knowledge and talents in practice.

2. Practice of Specialty Skills

This practice aims at training students' English professional skills to polish English listening, speaking, reading, writing and translating abilities. In the lower grades, the practice of English skills mainly focuses on strengthening language foundation to acquire pure pronunciation, fluent expression, standardized writing and abilities of acquiring English information by appreciating English movies, learning to sing English songs and conducting English debates. Senior students attach importance to improving their English-applying abilities, and the design of practice teaching content should help to enrich the students' mind with linguistic theoretical knowledge, literary knowledge, cross-cultural communication knowledge and professional knowledge. For example, the practice of analytical reading and writing can be carried out in combination with the original reading of British and American literature. Subjects like English speaking contests, interpreting practice and translation training can be conducted along with the hot issues of social economy, culture, life, history and art, so that students highlight abilities of professional knowledge application, logical thinking, problem-solving and teamwork cooperation.

3. Practice of Normal Skill

In order to fully play an exemplary role, English majors in normal universities, as future English teachers, are supposed to apply English accurately and skillfully. What's more, they'd make best of modern educational technology 
and computer operating system for teaching design, courseware making and classroom teaching. Therefore, the practice of normal skills includes English and Chinese calligraphy, training of teacher's oral expression, teaching design and making courseware. Of course, trial teaching as well as micro-course presentation is also quite meaningful practice. To highly arouse students' much attention, the authority of the university ranks the courses of teachers' skill practice as the compulsory subjects in the curriculum system. Teachers give theoretical guidance in the form of lectures, and students do practice independently out of class. In due time, contests of normal skills are held to motivate students for better progress, and academic credits are calculated in the final comprehensive assessment of the corresponding courses.

4. Instructing and Teaching Practice

Teaching practice mainly includes educational probation and classroom trial teaching experiences. Educational probation helps students to obtain self-education from on-the-spot observation, which is generally developed in the second year or third year of college study. It aims to clear the professional vision and requirements for normal students. While observing and experiencing the teaching process, students witness the communicating ways between teachers and students in the real teaching environment, truly perceive different teaching styles and teaching arts, master teaching procedures, understand teaching reform and contents of class management. English classroom teaching practice is to put educational and English theoretical knowledge learned in class into professional practice, thus students further consolidate theoretical knowledge and cultivate the practical abilities of using language in foreign language teaching work. The basic theories, knowledge and skills students have mastered are comprehensively used in various teaching practical activities such as listening to lectures, preparing lessons and evaluating classes in teaching and instructing practice. Gradually, students learn to understand the nature and law of English teaching so as to improve vocational skills and students' teaching abilities.

5. Practice of Academic Research

To cultivate sense of academic research, teachers can direct students to write course papers and graduation desertions; In addition, students also actively participate in scientific research projects, listen to professional academic lectures and engage in other practical activities, which helps students to know the basic methods of doing scientific research and cultivate students' abilities of academic investigation, literature retrieval and comprehensively applying the knowledge they have learned to analyze and solve problems. If students build up these qualities, they will lay foundation for their future development of scientific research and innovation abilities.

\section{Practice Teaching Mode}

In 2007, the Ministry of Education issued the document Opinions of the Ministry of Education on Further Deepening Undergraduate Teaching Reform and Improving Teaching Quality in an All-round Way, which requires that the accumulated credits (hours) of all practice teaching links involved in the teaching plan of humanities and social sciences majors should generally not be less than $15 \%$ of the total credits (hours). Practice teaching permeates the whole process of education from lower grade to higher grade, and it mainly includes three modes: in-class practice teaching, after-class practice teaching and off-campus practice teaching.

1. In-Class Practice Teaching

The chief goal of educating undergraduate English majors is to cultivate students' basic language skills and professional teaching skills, and most English courses are characteristic of practical application. In-class practice teaching is mainly completed through the relevant courses set up in the curriculum schedule. These courses mainly include Basic English, English Listening, English Reading, English Pronunciation, English Speaking, English Writing, Interpretation, Translation, Modern Educational Technology, Mandarin Chinese and other subjects. Classroom teaching of these courses adheres to the student-centered teaching philosophy, and teachers mainly direct students into understanding learning theories with aid of intensive lectures and innovating teaching methods. For example, "task-based" and "project-based" learning methods are introduced into foreign language teaching, or language scenarios are actively created to guide students to participate in language practice activities of listening, speaking, reading, writing and translating. At the same time, teachers pay full attention to supervision of students' participation in classroom practice activities, and teachers strictly record and evaluate students' performances in classroom practice activities, trying to create atmosphere in which students are willing to be actively engaged in classroom learning practice.

2. After-Class Practice Teaching

Classroom teaching is limited in time and space, and it is impossible for all students to participate in language practice activities in class. In order to enrich the forms of practice teaching, Firstly, Teachers should strengthen the supervision of extracurricular study and strictly implement the tutorial guidance (The tutorial guidance means that every teacher is consistently responsible to communicate with a group of students in free time; the teacher, acting as a tutor, regularly inspects the completion of extracurricular learning tasks assigned to students and helps to resolve their problems in study and life). Secondly, full use is made of the language experimental equipment to improve the efficiency of using resource and train language skills in their spare time. Thirdly, the school of foreign languages frequently organizes various extracurricular activities to arouse students' interest in professional learning and stimulate their curiosity for English culture, such as English salon, English reading contest, English writing contest, English debate contest, English-Chinese interpretation and translation competition, British-American knowledge contest, English drama contest, college students' speech forums, classic reading activities and so on. For the fourth, prestigious experts and scholars are invited to give academic lectures, so that students can broaden their professional horizons and 
deepen the academic insights. Last but not least, it is equally central to ensure that the student writes a graduation thesis of high quality. Graduation thesis is not only an in-depth examination of students' professional level, but also an important professional practice teaching means. Through thesis writing, students master certain researching method, which lays a foundation for later independent exploration into study.

3. Off-campus Practice Teaching

Off-campus practice teaching mainly includes professional probation, teaching internship and provincial or national professional competitions. According to the teaching plan, students conduct one-week probation in the fourth and sixth semester, so that English majors can step into primary or secondary schools to observe how English teachers demonstrate classes. From this, students have a preliminary understanding of the basic requirements and teaching processes of English class. In the eighth semester, students are assigned to various teaching practice bases for internship. The task of professional practice is completed under the guidance of the college teachers specialized in English methodology and the skillful middles school English teachers who guide students to familiarize themselves with the practice work gradually and try to carry out teaching work independently. At the same time, the college attaches great importance to participating in various provincial and national competitions, such as "Mid-west English Translation Competition", "College Students Teaching Contest", "National Oral Evaluation Competition" and so on. According to statistics in recent three years, English majors have won more than 100 awards in various professional competitions: one national award and seven provincial awards for English Reading and Writing Competition; one national prize and one provincial prize in the English Debate Competition; six provincial prizes in the English Speech Contest; two provincial awards in the English Teaching Competition; fifty-five provincial awards for English Interpretation and Translation Competition; twenty-one prizes for the National Oral Test (2019).

\section{Safeguarding Measures of Practice Teaching}

In order to set up more favorable teaching conditions and practical environments for cultivating practical and innovative foreign language talents, the authority of the university puts much emphasis to construction of software and hardware in foreign language practice teaching, so that students can effectively combine theoretical teaching with practical teaching to absorb culture through language and study language from culture.

1. Intensifying Practice Curriculum

According to the National Standard for Teaching Quality of Foreign Languages and Certification Standard for Secondary Education Majors, the new talent-training program in 2020 has set a large number of practical courses such as Listening and Speaking Practice, Chinese and English Calligraphy, Comprehensive English Skill, Curriculum Design, Graded English Reading, Education and Teaching Probation, Graduation Thesis (Design), Trial Teaching Practice, Labor, etc. The number of practical courses is 30 credits in all, accounting for about 18 percent of the total credits. In addition, combined with the new content, new system and the specific situation of professional practice, brand-new practical teaching materials can be compiled, such as Question-and-Answer Teaching Practice, Interactive Teaching Practice etc., so as to continuously enrich the practical course content.

2. Optimizing Practice Teaching Staff

The foreign languages school has bred a team of teachers with rich teaching experience and strong practical abilities. Firstly, excellent middle school English teachers are invited to act as tutors and present demonstrative classes for college students. Every off-campus tutor as well as each of the foreign language school teachers is responsible to steer several students in their professional study. The off-campus tutors who offer vocational guidance are the English teaching backbones, and most of them grasp advanced foreign language teaching concepts with remarkable foreign language teaching achievements. Simultaneously, college teachers also walk into middle school class to enrich practical teaching knowledge. Among the staff members involved in practice teaching, nearly $30 \%$ of the foreign languages school teachers have been appraised with senior professional titles, and more than $50 \%$ are certified with mid-level professional titles.

3. Improving Practice Teaching Platforms

Supported by the Basic Foreign Language Teaching Experimental Center, the foreign languages school has set up two simultaneous interpretation studios, an English translation studio, a situational language laboratory and eight standard language laboratories. The simultaneous interpretation studio is used for the practical training of simultaneous interpretation and consecutive interpretation courses, so that students can acquire language edification and practice in simulated situations. The English translation laboratory helps to create interactive teaching mode of translation course through translation practice, correction of translation homework and feedback of homework annotations on the platform. The English situational lab provides students with an independent language learning environment for students to practice speaking and listening. It can be used as a training place for English speaking, debating, broadcasting and recording English programs. It can also work for appreciating English films or videos, performing short English dramas and hosting English parties. The college also has equipped labs with about 700 seats, which fully satisfy the demands of teaching practice for listening courses. In addition, relying on the rich learning resources and technical support of the publishing house, the school has invested into a foreign language autonomous learning system loaded with online courses, audio/video materials, e-books, multimedia courseware and proficiency tests etc. Such autonomous learning system stimulates students to make use of the resource pool efficiently, and improves the abilities of applying foreign language skills step by step, which provides intellectual support for English practice teaching task. 


\section{Fortifying Practice Teaching Bases}

In order to meet the need of English practice teaching, the university actively develops close contacts with primary education institutions and has established a number of stable practice bases. The practice bases for English majors are located in Dazhou No.1 Middle School, Dazhou Senior Middle School, Dazhou Middle School, Dachuan Middle School, Tongchuan No.7 Middle School, Tongchuan No.8 Middle School and Tongchuan No.1 Elementary School, together with more than 30 primary and secondary schools in other cities. English teachers and students regularly hold educational and teaching seminars in these practice bases. As an important forum for students' language training, practice bases ensure of smooth operation for students' professional probation and internship.

5. Enforcing Practice Teaching Administration

The foreign languages school has established an evaluation system of practice teaching quality assessed by practice teaching supervisors, peer experts and students. Through assessment of practice teaching, the motivation mechanism of assessment and evaluation can be used to arouse working enthusiasm of practice teaching staff. For those who have made outstanding contribution to practice teaching work, they would be praised and rewarded, and the teachers are given priority to their professional promotion. At the same time, the practice teaching achievements strictly determine whether the students can get qualified grades of the corresponding courses, and the total credits of practice teaching courses should be regarded as one of the compulsory criteria for graduation from college.

\section{CONCLUSION}

It is one of the important contents of higher education to construct a practical teaching system with the aim of improving teaching quality, the demand of technological progress and social development for talents, the ability training of students as the basis, the cultivation of comprehensive quality and innovative spirit as the core, and the improvement of students' professional quality as the orientation. The Ministry of Education points out that it is necessary to attach great importance to practice links and improve students' practical abilities in the document Several Opinions on Deepening Undergraduate Teaching Reform and Improving Teaching Quality in an All-round Way. Therefore, teachers in colleges or universities should update their educational concepts of cultivating students' practical abilities and innovative entrepreneurial spirits, adhere to the idea of equally emphasizing practical teaching and theoretical teaching, and infiltrate practice teaching contents into the whole educational process. With the mission of cultivating would-be English teachers, the normal English major should always focus on teachers' professional quality to deepen the reform of practice teaching contents and methods, continuously improving English language competence and teaching skills through diverse practice teaching platforms, so as to truly achieve the goal of training well-qualified English teachers in primary and secondary schools with solid foundation, great abilities and new mindsets.

\section{REFERENCES}

[1] Duan, Ch. (2009). Thinking and Practice of Practical Teaching Content System for English Majors. Journal of Chengdu University of Technology, (3), 84-89.

[2] Higher Education Teaching Steering Committee. (1998). Some Opinions on the Reform of Undergraduate Education for Foreign Languages Majors in the 21st Century. Foreign Language World, (4), 1-6.

[3] Krashen, S. (1982). Second Language Acquisition and Second Language Learning. Oxford: Pergamon Press.

[4] Li, X.M. (2019). Audit and Evaluation Report of Foreign Languages School, Sichuan University of Arts and Sciences, April 20.

[5] Shi, M. Zh. (2009). "Learning+Acquisition" Rethinking the Foreign Language Learning mechanism. Teaching and Research, (2): 54-58.

[6] Shu, D. F. \& Zhuang, Zh. X. (1999). Modern Foreign Language Teaching Theory, Practice and Method. Shanghai: Shanghai Foreign Language Education Press.

[7] Steering Committee of Foreign Language Teaching in Colleges and Universities. (2000). Syllabus of English Major in Colleges and Universities. Beijing: Foreign Language Teaching and Research Press.

Kang Liu, a visiting scholar in U.S., is currently a lecturer of English at School of Foreign Languages, Sichuan University of Arts and Science, Dazhou, China. His research interests cover English language, English teaching and culture of English-speaking countries. 